\title{
Hyperspectral VNIR-spectroscopy and imagery as a tool for monitoring herbicide damage in wilding conifers
}

\author{
Rebecca C. Scholten $(1)$ Joachim Hill - Willy Werner · Henning Buddenbaum • \\ Jonathan P. Dash • Mireia Gomez Gallego • Carol A. Rolando • \\ Grant D. Pearse $\cdot$ Robin Hartley $\cdot$ Honey Jane Estarija $\cdot$ Michael S. Watt
}

Received: 17 February 2019/Accepted: 8 July 2019/Published online: 11 July 2019

(C) The Author(s) 2019

\begin{abstract}
Wilding conifers, the naturally regenerated scions of exotic conifer species, are a major ecological and economic issue in New Zealand. Hyperspectral imagery could provide a useful means of monitoring the efficacy of wilding control measures but little research has examined this possibility. Data were collected from an experiment, that included thirty-nine young Pinus contorta (Douglas) trees allocated to a control and two herbicide treatments (triclopyr butoxyethyl ester and diquat dibromide monohydrate). The objectives of this research were to examine the temporal impacts of herbicide on needle discolouration, spectral properties and tree physiology and to develop models to predict photosynthetic parameters
\end{abstract}

R. C. Scholten $(\bowtie) \cdot$ J. Hill $\cdot$ H. Buddenbaum

Environmental Remote Sensing and Geoinformatics, Trier University, 54286 Trier, Germany

e-mail: r.c.scholten@vu.nl

W. Werner

Geobotany, Trier University, 54286 Trier, Germany

J. P. Dash · M. Gomez Gallego - C. A. Rolando ·

G. D. Pearse - R. Hartley - H. J. Estarija

Scion, Private Bag 3020, Rotorua, New Zealand

M. S. Watt

Scion, 10 Kyle Street, Christchurch, New Zealand

Present Address:

R. C. Scholten

Faculty of Earth and Life Sciences, Vrije Universiteit Amsterdam, $1081 \mathrm{HV}$ Amsterdam, The Netherlands from hyperspectral data. In accordance with obvious discolouration on the first day after treatment, values of net photosynthesis rate $(A)$, electron transport rate $(E T R)$, stomatal conductance $(G)$ and optimal quantum yield of photosystem II $\left(F_{\mathrm{v}} / F_{\mathrm{m}}\right)$ declined rapidly for plants treated with diquat. Discolouration following application of triclopyr was not evident before the second week, and values of $A, E T R, G$ and $F_{\mathrm{v}} / F_{\mathrm{m}}$ declined slower than those of diquat. Of the tested narrow-band spectral indices calculated from needle spectra photochemical reflectance index (PRI) exhibited the strongest correlation with the four photosynthetic parameters and $R^{2}$ values between PRI and $A, F_{\mathrm{v}} /$ $F_{\mathrm{m}}$, ETR and $G$ were, respectively, 0.53, 0.46, 0.68 and 0.29 . Models that used raw spectra as inputs showed that sparse partial least squares (SPLS) outperformed the three other approaches tested (PLS, Support Vector Machines, Elastic Net) and $R^{2}$ values using this approach for $A, F_{\mathrm{v}} / F_{\mathrm{m}}, E T R$ and $G$ were, respectively, $0.64,0.62,0.65$ and 0.42 .

Keywords Hyperspectral - Lodgepole pine · Wildings · Invasion ecology $\cdot$ Stress detection · Herbicides

\section{Introduction}

Translocation of plants outside of the geographic region in which they evolved has facilitated the 
development of highly productive agricultural and plantation forestry systems. Plants are deemed to be exotic when they are located in geographic regions where they did not evolve and exotic plants can become invasive when they reproduce freely in their new environment (Richardson et al. 2014; Richardson and Rejmanek 2004). For several decades it has been apparent that exotic non-woody plants adversely affect many ecosystems around the world following their intentional or unintentional spread through human activities. In recent years, it has become evident that exotic trees are also becoming invasive in many environments (Richardson and Rejmánek 2011) and reports of their spread and adverse impacts have been reported from many regions (Nuñez et al. 2017).

Throughout temperate areas of the southern hemisphere, a small number of introduced conifer species that evolved in the northern hemisphere are the cornerstone of the plantation forest industry. These planted forests are frequently fast growing and also tolerant of poor growing conditions. They are also exempt from damage posed by harmful biotic agents often present in their native range meaning there are fewer risks posed to their productive and reproductive potential. These traits enable these conifer species to provide significant economic, ecological, and social benefits when planted in productive forest systems in southern hemisphere countries such as New Zealand, Australia, and Chile. However, the same evolutionary traits that make them excellent timber species mean that they can often out-compete indigenous vegetation outside of their natural range (Farjon and Farjon 2008).

In New Zealand, conifers constitute over $95 \%$ of the planted area that supports the forest products industry. The significant economic benefits of these forests include the provision of over $\$ 5$ billion per annum in exports alone and direct employment of 11,000 people (NZFOA 2018). However, several conifer species including Pinus contorta (Dougl.), $P$. mugo Turra, P. nigra Arnold and Pseudotsuga menziesii (Mirb.) Franco have been spreading from commercial plantations, farm shelterbelts and woodlots for over 100 years into indigenous grasslands, shrublands, and even forested areas. The area affected by invasive exotic conifers is thought to cover approximately 2 million ha and is believed to be increasing at a rate of $6 \%$ annually (Anon 2011;
McAlpine et al. 2016). The area covered by these wildings has resulted in an economic and ecological cost that is increasingly deemed to be unacceptable by New Zealand society (Dash et al. 2017a).

Significant research efforts are being applied to prevent the further spread of this invasion wherever possible or at least to prevent invasion into the most valued landscapes (Mason et al. 2017). These efforts require accurate mapping tools and effective control methods to efficiently distribute scarce resources. The control and elimination of invasive exotic conifer over large areas with difficult terrain is partly reliant on aerial herbicide application. The development of herbicides for invasive exotic conifer control is well advanced with several options available to land managers although the efficacy of the techniques developed is variable (Gous et al. 2014, 2015). The widespread application of aerial herbicides may also have significant environmental consequences (Garrett et al. 2016) and so maximising the efficiency of the chemicals applied is imperative. Consequently, the development of methods that can monitor the effects of herbicide application on invasive, exotic conifers over large areas will become critically important for quantifying the efficacy of control and guiding the application of appropriate levels of herbicide.

Herbicides disrupt a range of physiological functions in plants causing significant stress that leads to mortality if the plant cannot recover. Several studies have researched remote sensing methods that can monitor the effects of herbicides on agricultural species (Zhao et al. 2014) and plantation-grown conifers at a range of spatial scales (Dash et al. 2017b). Most commonly, multispectral and hyperspectral sensors are used for this task with data acquired from platforms ranging from proximal spectrometers to space-borne satellites. The varying spectral range and resolution of these sensors define the spectral vegetation indices that can be calculated and therefore their sensitivity to capture herbicide-induced physiological changes.

Most studies in this area have been concerned with using remote sensing to develop early detection methods to quantify the effects of spray drift before the symptoms of injury become visually apparent. Vegetation indices have been widely used to detect stress from herbicide application in crop plants. For example, herbicide damage on soybean crops was detected using a range of indices (Huang et al. 2010) 
and this method was refined by identifying appropriate indices using the physically-based leaf radiative transfer model PROSPECT (Jacquemoud and Baret 1990). This approach provides a means to generalize results to a wide range of leaf structures and growing conditions by parameterising the model with the appropriate values for each context (Zhao et al. 2014). Spectral derivatives have also been successfully used to predict crop injury in soybean and analyses show these derivatives to be more accurate than a large number of vegetation indices (Yao et al. 2012). In mature stands of Pinus radiata (D. Don) vegetation indices that included the near-infrared and red edge regions were found to be capable of detecting herbicide-induced stress using imagery collected from an unmanned aerial vehicle (UAV) (Dash et al. 2017b) and from a commercial Earth-observing satellite (Dash et al. 2018). Although useful from a practical perspective the inference that can be drawn from these studies is limited because the specific physiological changes occurring in the studied trees were not monitored.

The popular spectral indices and features derived from multi-spectral reflectance data suffer from two main limitations. Firstly, indices such as the normalised difference vegetation index (NDVI) that are typically derived from multispectral data, are sensitive to low chlorophyll content but tend to saturate at higher chlorophyll levels. Secondly, although multispectral data have been shown to be of use (e.g. Dash et al. 2018), the coarse spectral resolution and limited spectral range of these data do not allow for a detailed assessment of the wavelengths that are most closely correlated with physiological change and needle necrosis (Asner and Martin 2009; Hill et al. 2019). Overcoming these limitations requires the use of hyperspectral data with a finer spectral resolution and greater spectral range that can be used to more comprehensively examine changes in photosynthesis and needle death associated with herbicide application.

The objective of this study was to use close-range hyperspectral data to develop methods to detect herbicide stress in Pinus contorta (Douglas) which is the most widespread and invasive exotic conifer in New Zealand (McAlpine et al. 2016). Using data collected from a glasshouse trial that involved monitoring the effects of two herbicides, with contrasting modes of operation, on $P$. contorta, the objectives of this research were to (1) identify the impacts of herbicide on needle discolouration, spectral properties and four key photosynthetic parameters, (2) identify whether vegetation indices, derived from hyperspectral data, could be used to detect the impacts of treatments before visual changes were evident and (3) compare the precision of models developed to predict key photosynthetic parameters that were constructed using either vegetation indices or raw spectral information.

\section{Materials and methods}

Plant material and treatments

Pinus contorta plants invading native ecosystems were collected from the field in the central North Island of New Zealand between February and March 2017. Tree age, as estimated from the number of whorls, averaged 4 years and ranged from 3 to 6 years. Following collection, plants were placed in a greenhouse to acclimatise for the 9 months preceding the trial. Plants were fertilised with phosphorus and nitrogen and irrigated as required over the duration of the experiment. At the start of the experiment tree height, root collar diameter and canopy width, respectively, averaged $157 \mathrm{~cm}$ (range 110-205 cm), $3.34 \mathrm{~cm}$ (range $2.17-5.10 \mathrm{~cm}$ ) and $74.3 \mathrm{~cm}$ (range $48-135 \mathrm{~cm})$.

Stratified random sampling was used to allocate the thirty-nine trees to the three treatments that included an untreated control and two herbicide treatments. The two herbicides applied included the systemic pyridine herbicide, triclopyr butoxyethyl ester (Grazon, $600 \mathrm{~g}$ $\mathrm{L}^{-1}$ triclopyr, Dow AgroSciences Ltd) and the contact herbicide diquat dibromide monohydrate (Reglone, $200 \mathrm{~g} \mathrm{~L}^{-1}$ diquat dibromide, Syngenta Australia). Both of these herbicides are used operationally in wilding conifer control, however, typically they would be applied to much larger trees $(>5 \mathrm{~m}$ ) at higher rates. The rates of the herbicide treatments used in this trial are summarised in Table 1 and were based on rates known to be effective on smaller trees (Gous et al. 2010).

Triclopyr is a pyridine carboxylic acid and is a synthetic auxin (mode of action: WSSA Group 4), inducing an auxin-type response in broadleaves. The herbicide mimics the plant hormone auxin that acts 
Table 1 Rates and products of the treatments used in the trial. Treatments were applied with a track sprayer calibrated to deliver the equivalent of $300 \mathrm{~L} \mathrm{ha}^{-1}$ using TT8003 nozzles.
The nozzles used in the spray operation produce droplets with a volume mean diameter of 350-500 $\mu \mathrm{m}$ and all treatments were applied with the equivalent of $1.5 \mathrm{~L}$ Pulse

\begin{tabular}{llcc}
\hline Active ingredient & Product used & AI kg ha & Product (1/ha) \\
\hline Triclopyr & Grazon $(600 \mathrm{~g} / \mathrm{L}$ triclopyr) & 12.0 & 20.0 \\
Diquat & Reglone $(200 \mathrm{~g}$ a.i. g/kg diquat $)$ & 3.0 & 15.0 \\
\hline
\end{tabular}

like indole acetic acid and when administered at effective doses, causes uncontrolled and disorganised plant growth that leads to plant death. The exact mode of action of triclopyr has not been fully described but is believed to acidify and loosen cell walls allowing cells to expand without normal control and coordination. Low concentrations of triclopyr can stimulate RNA, DNA and protein synthesis leading to uncontrolled cell division and growth and ultimately vascular tissue destruction (Tu et al. 2001). Conversely, high concentrations of triclopyr can inhibit cell division and growth (Tu et al. 2001). Effects on growth are observed in meristematic tissues (observed in the twisted growth of new tissues). It is a selective, systemic herbicide absorbed by foliage and roots with translocation throughout the plant. The mode of action does not directly affect the photosynthetic activity/cycle. Grazon contains triclopyr as the butoxyethyl ester and is widely used in wilding conifer control.

Diquat is a bipyridylium that belongs to the group of herbicides that are photosynthesis inhibitors, specifically photosystem 1 (PSI) inhibitors (WSSA Group 22). Upon contact with the plant foliage these herbicides act by penetrating and destroying the cell lipid bilayer leading to the breakdown of the cell membranes-i.e. they are cell membrane disruptors (Sherwani et al. 2015). These are non-selective herbicides and are also known as PSI electron diverters as they accept electrons from PSI and, in the process generate herbicide radicals. Cell disruption leads to leakage of cell cytoplasm, which leads to wilting and eventual plant death. Diquat is thus a non-selective herbicide and also a desiccant, absorbed by the foliage with some translocation in the xylem. The likely response will be rapid with a breakdown of cuticle and needle tissue. This herbicide has been used widely in the past to control wildings, often in combination with fire. The most widely used product is Reglone. More recently, most operational programmes use triclopyr as the main active ingredient, however, diquat is still sometimes applied on smaller trees where scattered infestations occur.
On March 20th 2018, the two herbicide treatments were applied using a calibrated boom sprayer, fitted with Turbo Teejet nozzles (TT8003; Spraying Systems Co. Wheaton, Illinois, USA) at a pressure of $2.6 \mathrm{kPa}$, and at a height of $2 \mathrm{~m}$ above the seedling canopy. These nozzles produced a spray characterised by droplets with a volume mean diameter (VMD) ranging from 350 to $500 \mu \mathrm{m}$. The application protocol was designed to closely approximate a boom spray operation typically used to treat dense infestations of mature conifers where $400-600 \mathrm{~L} \mathrm{ha}^{-1}$ per hectare spray solution with droplets with a VMD of $350 \mu \mathrm{m}$ is used. After spraying, the trees were left to dry before being shifted back to the greenhouse on March 21st, 2018, when the first measurements took place.

\section{Measurements}

Measurements were taken with varying degrees of frequency over the course of the experiment, which ranged from the week before treatment $(\mathrm{T}-1)$ to 5 weeks following treatment $(\mathrm{T}+5$ weeks). Visual assessments of the degree of foliage discolouration and hyperspectral imagery were collected weekly. Measurements of photosynthesis and chlorophyll fluorescence were taken three times per week during the first 2 weeks and twice per week for the remainder of the experiment. Measurements of needle spectra were taken two to three times per week over the course of the experiment, apart from the fourth week following treatment during which only one measurement was taken. Photosynthesis, chlorophyll fluorescence and needle spectra were measured on currentyear needles of one randomly selected branch in the uppermost crown area of each tree.

\section{Visual observations}

The degree of foliage discolouration in terms of needle chlorosis and necrosis was visually assessed by a skilled observer. Trees were scored based on a rating 
scale ranging from 0 to 100 with 0 and 100 , respectively, denoting no discolouration and complete discolouration of the tree crowns.

\section{Gas exchange and chlorophyll fluorescence measurements}

Instant light-response curves were performed on a subsample of 19 randomly sampled plants to assess saturating levels of the photosynthetic photon flux density $\left(\mathrm{PPFD}_{\mathrm{sat}}\right)$ at maximum apparent electron transport rate $(E T R)$, using an Imaging-PAM chlorophyll fluorometer (M-series, Walz, Effeltrich, Germany). The value of PPFD sat $\left(735 \mu \mathrm{mol} \mathrm{m} \mathrm{m}^{-2} \mathrm{~s}^{-1}\right)$ was used in all the gas exchange and chlorophyll fluorescence measurements. Hourly time series measurements of in situ chlorophyll fluorescence and gas exchange were performed from 7 am to $3.30 \mathrm{pm}$ (using $30 \mathrm{~min}$ at each time slot) in a random subsample of 8 grafts using a coupled chlorophyll fluorescence and gas-exchange system with a leaf clip (Imaging-PAM M-Series and GFS-3000, Walz, Effeltrich, Germany) at $400 \mathrm{ppm} \mathrm{CO}_{2}$ concentration, $20{ }^{\circ} \mathrm{C}$ cuvette temperature, $60 \%$ relative humidity and at PPFD $_{\text {sat }}$. We fitted a linear mixed model for each response variable with 'plant identity' as a random factor and 'time slot' as a fixed factor (Pinheiro et al. 2014). As the measurements at 7 a.m. and at 3 p.m. were significantly different from the others, we restricted measurements to between 8 a.m. to 2.30 p.m. To further minimize the variability due to the time of the day when measurements were performed, we assessed the plants in 13 blocks that included one plant from each treatment.

Net photosynthetic rates $(A)$, stomatal conductance $(G)$ and ETR were measured after a 2-min preillumination period, at $400 \mathrm{ppm} \mathrm{CO}_{2}$ concentration. Conditions in the cuvette were kept constant within each block of measurements and ranged between the following values: cuvette temperature at $17-25^{\circ} \mathrm{C}$, light intensity at $\mathrm{PPFD}_{\text {sat }}$ and relative humidity at 14,500-19,000 ppm. We performed dark-adapted measurements by covering twigs with a black cloth for $30 \mathrm{~min}$ to obtain the minimal $\left(F_{0}\right)$ and maximal fluorescence $\left(F_{m}\right)$. The value of the optimal quantum yield of photosystem II (PSII) $\left(F_{v} / F_{m}\right)$ was calculated using $F_{v} / F_{m}=\left(F_{m}-F_{0}\right) / F_{m}$.
Needle spectroscopy

\section{Measurements}

The radiative properties for needles were measured using an HR2000 + High-speed Miniature Fibre Optic spectrometer (Ocean Optics, Inc., FL). The built-in 2048-element linear silicon CCD array allows for a spectral range of 200-1100 nm and a signal-tonoise (SNR) ratio of 250:1 at full signal. The acquired spectra, which have a sub-nanometre spectral resolution (approx. $0.5 \mathrm{~nm}$ ), were managed using the operating software OceanView.

The difficulties associated with the three-dimensional shape of the conifer needles were mitigated through including six needles from each selected shoot. These needles were collected and aligned with the abaxial side up on a $1 \mathrm{~cm}^{2}$ piece of non-reflecting foam using adhesive putty with inter-leaf gaps of ca. $1 \mathrm{~mm}$ wide to minimise the influence of scattering effects between the needles on the reflection signal. The spectrometer footprint $\left(<1 \mathrm{~cm}^{2}\right)$ was kept constant using an optical fibre cable attached with a fixed distance vertically above the sample area, and a connected collimating lens adjusted to near collimation. Measurements were taken in full sunlight to ensure integration times could be kept as short as possible to avoid changing cloud cover, and measurements were only taken inside the greenhouse during rain. Between samples, the integration time was adjusted between 1 and $100 \mathrm{~ms}$ according to the illumination. The illumination was measured using a Spectralon ${ }^{\circledR}$ diffuse reflectance standard, which acts as a Lambertian reflector. Ten scans per acquisition were averaged to improve the SNR ratio. Since longer integration times also decrease the noise, more spectra were averaged with smaller integration times as long as the illumination was stable. At least ten replicates were measured from each sample to ensure that a sufficient number of spectra remained after postprocessing. Each set of measurements included the measurement of the sample and two measurements of the reflectance standard taken before and after the sample and sets took between 2 and $10 \mathrm{~s}$. Measurements were taken after plants had acclimated to full sunlight for at least an hour and under a solar zenith angle not exceeding $60^{\circ}$ as proposed by Cogliati et al. (2015). 


\section{Processing}

The resulting radiance spectra were automatically processed in terms of wavelength calibration and nonlinearity, stray light and dark-current correction by the operating software OceanView. We also excluded spectra based on several quality criteria. Firstly, the white reference measurements before and after the sample measurement were compared, and all pairs with more than $10 \%$ variation were excluded as proposed by Cogliati et al. (2015). Secondly, all replicates of the same sample were compared to exclude divergent spectra due to measurement errors. Absolute reflectance factors and fluorescence were calculated from the sample spectra using the mean of the reference measurements taken before and after each sample measurement to approximately interpolate the reference measurements to the timing of the sample measurements.

\section{Hyperspectral imagery}

\section{Measurements}

A spectrograph-based Specim FX10 camera was used to acquire hyperspectral imagery. This instrument is a push-broom camera that captures 448 bands with wavelengths ranging from 400 to $1000 \mathrm{~nm}$ with a spectral full width half maximum (FWHM) of $5.5 \mathrm{~nm}$. The camera is designed for industrial applications and as such has a high maximum frame rate of 9900 frames per second with one band, and 330 frames per second using the full range of bands, as well as a high SNR of 600:1. The spatial sampling comprises 1024 pixels within a field of view of $38^{\circ}$. The image acquisition was managed using the provided Lumo Recorder software interface.

The camera was mounted on a tower-like construction about $2 \mathrm{~m}$ above ground, and a conveyor belt was used to move the plants through the field of view. The speed of the conveyor belt was adapted to fit the frame rate of the camera, which in turn was dependent on the exposure time, which had to be adjusted to the current illumination conditions. During the trial, the conveyor belt speed was kept constant and the frame rate was only adjusted to match the exposure time. A diffuse reflectance bar made of Spectralon ${ }^{\circledR}$ was attached at the edge of the field of view so that it was visible in every frame allowing changing illumination to be accounted for during post-processing.

\section{Processing}

The dark current subtraction and calibration were carried out in MATLAB (The MathWorks, Inc). Since no dark current images were acquired in parallel with the image acquisition, the correction was approximated using a set of retroactively acquired images. The mean over all four dark current test images, however, yielded very similar results, so that the error introduced by this procedure could be considered negligible.

For the reflectance images, the diffuse reflectance reference placed in the rightmost position of the image was detected by selecting the highest radiance values per row as well as its three adjoining pixels. All pixels were then divided by the mean of these white reference pixels row- and band-wise. Therefore, short-term differences in illumination could be accounted for (Gamon et al. 1997). As a last pre-processing step, the spectral smile effect, a wavelength shift in the spectral domain typically found in push-broom scanners, was corrected, and the striping of the images was removed. This was based on a measurement of the white reference bar covering the full width of the camera's field of view. The column mean of this image was calculated, and different striping widths were tested and compared visually. The best width according to visual assessment (45 pixels) was selected, and the striping factors derived from the aberration of the stripes from the grand mean were applied to all images.

\section{Derived indices}

Table 2 lists the hyperspectral indices used for early stress detection, which were based on needle spectra obtained from the spectrometer. The indices ranged from the photochemically based PRI (Gamon et al. 1997), which senses the state of xanthophyll epoxidation, to those measuring characteristics of the red edge and NIR plateau such as the red edge NDVI or the Zarco-Tejada-Miller red edge single ratio index (Zarco-Tejada et al. 2004). Furthermore, the simple greenness index reported by Moya and Flexas (2012) was included as an index solely based on the discolouration of green plant material, which can thus 
be interpreted as an estimate of the visual observations.

\section{Analysis}

All analyses were performed using software $\mathrm{R}$ version 3.5.1 (R Development Core Team 2014). Treatment changes in visual damage, spectra, the four photosynthetic parameters and hyperspectral indices were plotted against time. Using three plants, representative of the treatments, RGB true colour and PRI images were produced from data captured by the Specim camera, before treatment and during the following 5 weeks to compare treatment-induced changes (Figs. 1, 5). Linear mixed effects models computed with the nlme package version 3.1-137 (Pinheiro et al. 2018) were used to analyse the effects of herbicide treatment and the time after herbicide application on the spectral indices calculated from needle spectrometry (listed in Table 2) and the four photosynthetic parameters $(A, G$, $F_{v} / F_{m}$ and ETR). 'Plant identity' was included in the model as a random term to account for repeated measures.

Regression modelling was used to predict the four photosynthetic parameters using the vegetation indices described above and the needle spectra acquired for all treatments. For the models created using the vegetation indices, a range of functional forms was tested which included both linear and nonlinear models. For the models that used needle spectra as inputs, all wavelengths in the region of the highly variable $\mathrm{O}_{2}$-A band $(755-770 \mathrm{~nm})$ were excluded from the predictor set, since the needle spectra exhibited artefacts in this area. As the full spectral data included a large number of independent variables, we used modelling approaches that can accommodate a high number of predictors and the multi-collinearity present in this dataset. These approaches included elastic net, partial least squares, sparse partial least squares and support vector machines.

Partial least squares, PLS, (Wold 1966) is the most commonly used regression method for numerous, correlated predictor variables (Chauchard et al. 2004). It is a standard linear algorithm combining multiple linear regression with a feature construction method and has been widely used in chemometrics, biomedicine and spectroscopy (e.g. Nguyen and Rocke 2002; Thissen et al. 2004), and more specifically to assess plant traits and health from hyperspectral data (Buddenbaum et al. 2012; Moresco et al. 2017). The PLS regression using the kernel algorithm was performed in $\mathrm{R}$ using the pls 2.6-0 package (Mevik et al. 2011) and as suggested by Filzmoser et al. (2012), the number of latent variables was initially restricted to 20.

Elastic net (Zou and Hastie 2005) combines the advantages of ridge and lasso regularisation and has proved useful in fields such as chemometrics (Moresco et al. 2017) spectroscopy (Fu et al. 2011), geology (Dyar et al. 2012) and food quality analysis (Craig et al. 2014). Elastic net regression was performed in $\mathrm{R}$ with the caret 6.0-79 package (Kuhn 2008) using the glmnet algorithm (Friedman et al. 2010).

The use of variable selection methods such as elastic net is not restricted to regression purposes but can also improve standard methods such as partial least squares regression (Höskuldsson 2001; Wang et al. 2017). Therefore, sparse PLS (SPLS), which

Table 2 Selected hyperspectral indices that were used within this study

\begin{tabular}{|c|c|c|c|}
\hline Index & Characterisation & References & Equations \\
\hline Photochemical reflectance index (PRI) & Light use efficiency & Gamon et al. (1992) & $(\mathrm{R} 531-\mathrm{R} 570) /(\mathrm{R} 531+\mathrm{R} 570)$ \\
\hline Red edge NDVI & Red edge & & $(\mathrm{R} 750-\mathrm{R} 705) /(\mathrm{R} 750+\mathrm{R} 705)$ \\
\hline $\begin{array}{l}\text { Normalised phaeophytinization index } \\
\text { (NPQI) }\end{array}$ & $\begin{array}{l}\text { Chlorophyll } \\
\text { degradation }\end{array}$ & Penuelas et al. (1995b) & $(\mathrm{R} 415-\mathrm{R} 435) /(\mathrm{R} 415+\mathrm{R} 435)$ \\
\hline $\begin{array}{l}\text { Zarco-Tejada and Miller Red edge } \\
\text { single ratio index (RESRI) }\end{array}$ & Red edge & $\begin{array}{l}\text { Zarco-Tejada et al. } \\
\text { (2001) }\end{array}$ & $\mathrm{R} 750 / \mathrm{R} 710$ \\
\hline NDVI & & Rouse Jr et al. (1974) & $(\mathrm{R} 800-\mathrm{R} 670) /(\mathrm{R} 800+\mathrm{R} 670)$ \\
\hline $\begin{array}{l}\text { Structure independent pigment } \\
\text { index (SIPI) }\end{array}$ & Light use efficiency & Penuelas et al. (1995a) & $(\mathrm{R} 800-\mathrm{R} 445) /(\mathrm{R} 800+\mathrm{R} 680)$ \\
\hline Greenness Index (GI) & & $\begin{array}{l}\text { Zarco-Tejada et al. } \\
\quad(2001)\end{array}$ & R554/R677 \\
\hline
\end{tabular}



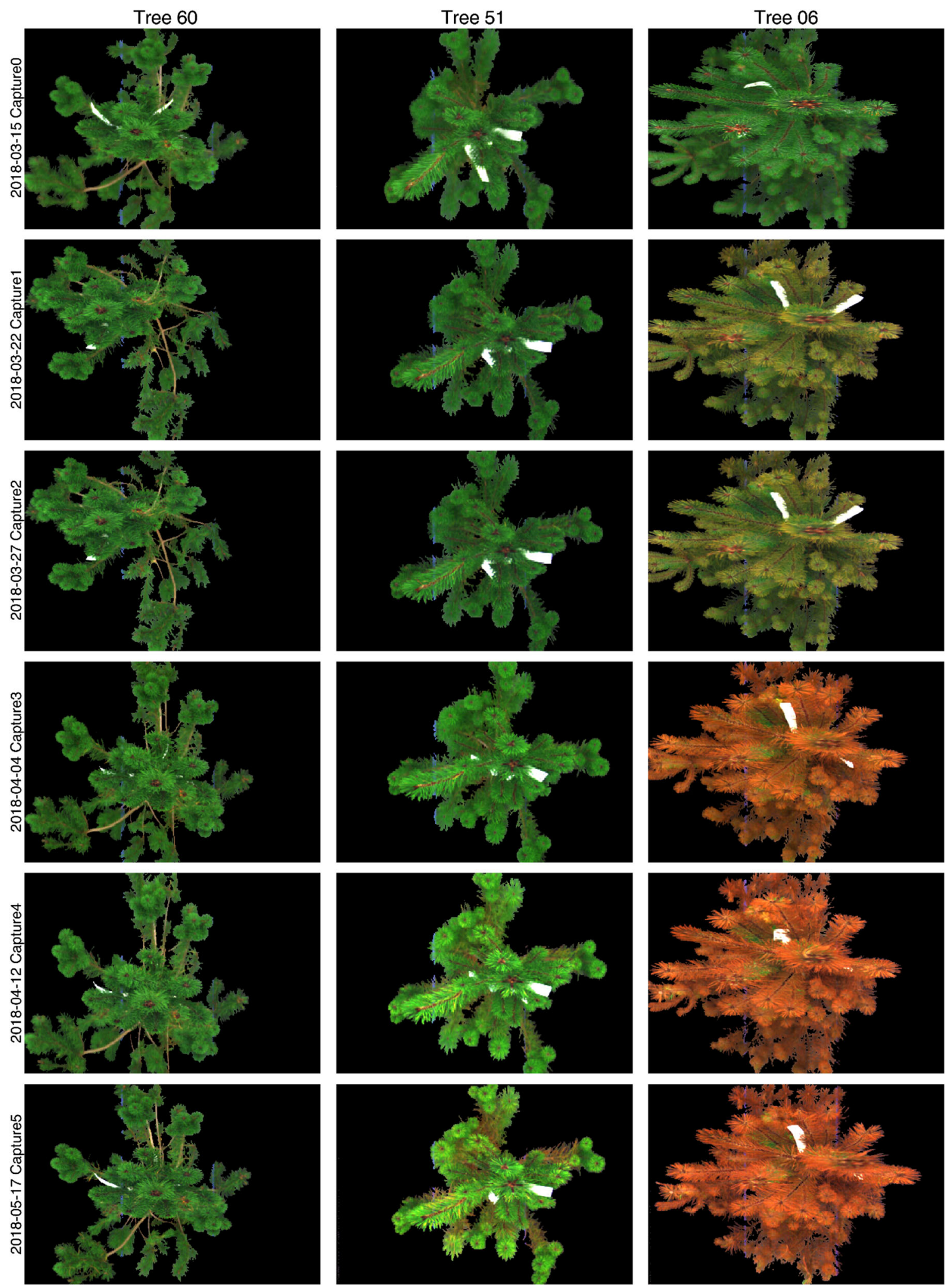
4Fig. 1 RGB images of representative plants from each treatment for all acquisition times, with images on each row from top to bottom, representing the time of treatment (0) followed by the 5 weeks following treatment (bottom $=$ week 5). Images shown in columns from left to right represent the control plant (plant 60) and plants treated with triclopyr (plant 51) and diquat (plant 6)

adapts elastic net penalties to perform PLS on a restricted set of predictors, was performed on the data using the spls package in R (Chun and Keleş 2010).

Support vector machines are machine learning methods widely used for spectral regression. Originally developed by Vapnik as a classification tool based on statistical learning theory, the algorithm was extended to regression problems by means of an $\varepsilon$ insensitive loss function (Vapnik 2013). SVM regression was performed using the $\mathrm{R}$ kernlab package (Karatzoglou et al. 2004), and the caret 6.0-79 package (Kuhn 2008). Linear and RBF kernels were compared on a subset of the datasets, and the more precise of both was applied to all datasets.

All models were constructed using ten-fold crossvalidation with five repeats. Parameters were tuned to optimise model precision for all four models. Model precision was assessed using the cross-validated coefficient of determination $R_{c v}^{2}$ (Wold et al. 2001) and loading plots were examined for the most precise model to determine spectral properties that had the most influence on photosynthetic parameters.

\section{Results}

Visual observations of treatment effects

Visual observations of discolouration showed little change for the control plants throughout the 3 weeks of the experiment, with values averaging respectively, 0 , 0.8 and $0.8 \%$ during weeks 1,2 and 3 (Table 3). Discolouration following application of triclopyr was not evident in week one $(0 \%)$ but these visual symptoms increased in weeks two $($ mean $=6.2 \%$ ) and week three $($ mean $=19 \%)$. Obvious discolouration was evident for plants treated with diquat on the day following treatment (mean $>40 \%$ ) and values during weeks 1, 2 and 3 averaged 68, 80 and $84 \%$ (Table 3). Compared to the control, significant increases in discolouration for plants treated with diquat and triclopyr were respectively noted 1 and 7 days after treatment (Table 4).

The RGB images of representative plants (Fig. 1) showed no visual change during the duration of the trial for the control treatment. Discolouration from triclopyr was evident 3 weeks after treatment. The plants treated with diquat showed discolouration a week after treatment and by 3 weeks after treatment needles were uniformly brown (Fig. 1).

Treatment changes in foliage spectra

Needle reflectance showed wide variation across the spectral range between the three treatments (Fig. 2). Within the control treatment, reflectance generally
Table 3 Visual observations of percent discolouration for each plant measured during the first three weeks (22nd March, 28th March and 4th April 2018) following treatment

\section{Plants selected for} illustrating changes in RGB and spectral indices are highlighted in bold

\begin{tabular}{llllllllllll}
\hline Triclopyr & 1 & 2 & 3 & Diquat & 1 & 2 & 3 & Control & 1 & 2 & 3 \\
\hline 13 & 0 & 10 & 20 & $\mathbf{1 1}$ & 70 & 80 & 80 & $\mathbf{3 1}$ & 0 & 0 & 0 \\
32 & 0 & 10 & 20 & $\mathbf{5 3}$ & 70 & 70 & 90 & $\mathbf{1 2}$ & 0 & 0 & 0 \\
27 & 0 & 0 & 10 & $\mathbf{6 7}$ & 80 & 80 & 90 & $\mathbf{3 6}$ & 0 & 0 & 0 \\
20 & 0 & 10 & 10 & $\mathbf{1 6}$ & 40 & 80 & 80 & $\mathbf{7 0}$ & 0 & 0 & 0 \\
63 & 0 & 10 & 20 & $\mathbf{6}$ & 60 & 70 & 80 & $\mathbf{6 4}$ & 0 & 0 & 0 \\
51 & 0 & 0 & 10 & $\mathbf{5 4}$ & 70 & 90 & 90 & $\mathbf{6 0}$ & 0 & 0 & 0 \\
59 & 0 & 0 & 10 & $\mathbf{4 5}$ & 70 & 80 & 80 & $\mathbf{6 6}$ & 0 & 0 & 0 \\
57 & 0 & 10 & 30 & $\mathbf{2 9}$ & 80 & 80 & 90 & $\mathbf{6 1}$ & 0 & 0 & 0 \\
52 & 0 & 10 & 40 & $\mathbf{6 8}$ & 80 & 90 & 90 & $\mathbf{5 8}$ & 0 & 0 & 0 \\
69 & 0 & 0 & 20 & $\mathbf{3}$ & 70 & 80 & 80 & $\mathbf{5 5}$ & 0 & 0 & 0 \\
26 & 0 & 0 & 20 & $\mathbf{6 2}$ & 60 & 80 & 80 & $\mathbf{4 0}$ & 0 & 0 & 0 \\
37 & 0 & 10 & 10 & $\mathbf{6 5}$ & 70 & 90 & 90 & $\mathbf{7 1}$ & 0 & 0 & 0 \\
17 & 0 & 10 & 30 & $\mathbf{1 9}$ & 60 & 70 & 80 & $\mathbf{4}$ & 0 & 10 & 10 \\
\hline
\end{tabular}


Table 4 Earliest day after treatment when the groups treated with diquat and triclopyr could be visually differentiated from the control group (first day when a discolouration difference of at least $10 \%$ could be observed) and significantly differentiated in the case of the photosynthesis and fluorescence parameters $\left(\mathrm{ETR}, F_{\mathrm{v}} / F_{\mathrm{m}}, A\right.$ and $\left.G\right)$

\begin{tabular}{llll}
\hline Metric & Diquat & Triclopyr & $R^{2}(\mathrm{lme})$ \\
\hline Discolouration & Day 1 & Day 7 & - \\
ETR & Day 1 & Day 2 & 0.87 \\
$F_{\mathrm{v}} / F_{\mathrm{m}}$ & Day 1 & Day 7 & 0.81 \\
$A$ & Day 1 & Day 1 & 0.77 \\
$G$ & Day 1 & Day 1 & 0.65 \\
\hline
\end{tabular}

slightly increased across all spectra with the most marked increases occurring within the range that exceeded $720 \mathrm{~nm}$. For plants treated with triclopyr, increases also occurred over time but were far more marked than the control within the 550-680 nm range (Fig. 2). Plants treated with diquat exhibited a level of change that was more pronounced than both other treatments from 650 to $700 \mathrm{~nm}$. Compared to the control, the reflectance in plants treated with diquat was reduced over time from 700 to $800 \mathrm{~nm}$ (Fig. 2).

Herbicide effects on photosynthesis

and chlorophyll fluorescence parameters

Time series measurements showed a marked decline in all measured parameters following application of herbicide (Fig. 3). For plants treated with diquat (green lines; Fig. 3) values of $A, E T R, G$ and $F_{\mathrm{v}} / F_{\mathrm{m}}$ declined sharply following treatment and reached minima at $1,25,18$, and 4 days after treatment, respectively $(0.5,0,12$ and $8 \%$ of control values, respectively). Following the strong initial decline, there was some recovery in $A, G$ and $F_{\mathrm{v}} / F_{\mathrm{m}}$ during the second week following treatment but ETR remained low. In contrast, in plants treated with triclopyr (yellow lines: Fig. 3), changes in those parameters generally took place later with the exception of $F_{\mathrm{v}} / F_{\mathrm{m}}$ which declined relatively rapidly. However all photosynthetic parameters reached similar minima to those treated with diquat. The minimum values for $A, E T R$, $G$ and $F_{\mathrm{v}} / F_{\mathrm{m}}$ in plants treated with triclopyr were 10,1 , 22 and $52 \%$ of control values, at 29, 29, 32, and 29, days after treatment, respectively.

For all four photosynthetic parameters, there were significant differences between treatments reported by the linear mixed effects models. For plants treated with diquat, all four photosynthetic parameters were significantly reduced below the control 1 day after treatment (Table 4). For plants treated with triclopyr, significant reductions below the control were noted 1 day after treatment for $A$ and $G$, but did not occur until 2 and 7 days after treatment for ETR and $F_{\mathrm{v}} / F_{\mathrm{m}}$, respectively.

Early stress detection using indices

Values of all four tested indices calculated from needle spectra and hyperspectral imagery showed marked reductions over time for both herbicide treatments (Figs. 4, 5). For all indices reductions were greatest for diquat (green lines, Figs. 4, 5). Values declined very quickly below the control immediately after treatment and then continued declining for the remainder of the experiment. In contrast, for plants treated with triclopyr, divergence in indices from the control was less pronounced (yellow lines, Figs. 4, 5). Although there was immediate divergence for PRI and to a lesser extent for reNDVI, values for control and triclopyr treated plants were very similar for GI and SIPI during the first 10 days after treatment, before declining in the treated plants (Fig. 4).

Although all indices were able to discriminate between the control and diquat there was wide variation in their effectiveness to identify differences between the control and triclopyr. The linear mixed effects models detected significant differences between the control and diquat between one and 2 days after treatment for all indices calculated form needle spectra (Table 5). However, only PRI was able to detect significant differences between the control and triclopyr 1 day after treatment. Significant treatment differences between these two treatments were only noted 10 days after treatment for both reNDVI and Red Edge Index and 18 days after treatment for SIPI and Greenness index (Table 5).

Changes in tree crown PRI through time for the three sampled trees, based on Specim data, show this index was able to reproduce the damaging effects of the herbicide very well also at crown level (Figs. 5, 6). PRI detected the two-phase impact of the diquat, with immediate reductions in PRI occurring in the first week and more substantial reductions in the third week (Figs. 5, 6). The more subtle changes that occurred within the triclopyr treatment were also clearly visible 
Fig. 2 Changes in mean needle spectra of control plants (top) and plants treated with triclopyr (middle) and diquat (bottom) over time. Lines of differing colour represent variation in the time of measurement with the gradient from dark to light blue, representing measurements taken, respectively, at the start and finish of the experiment
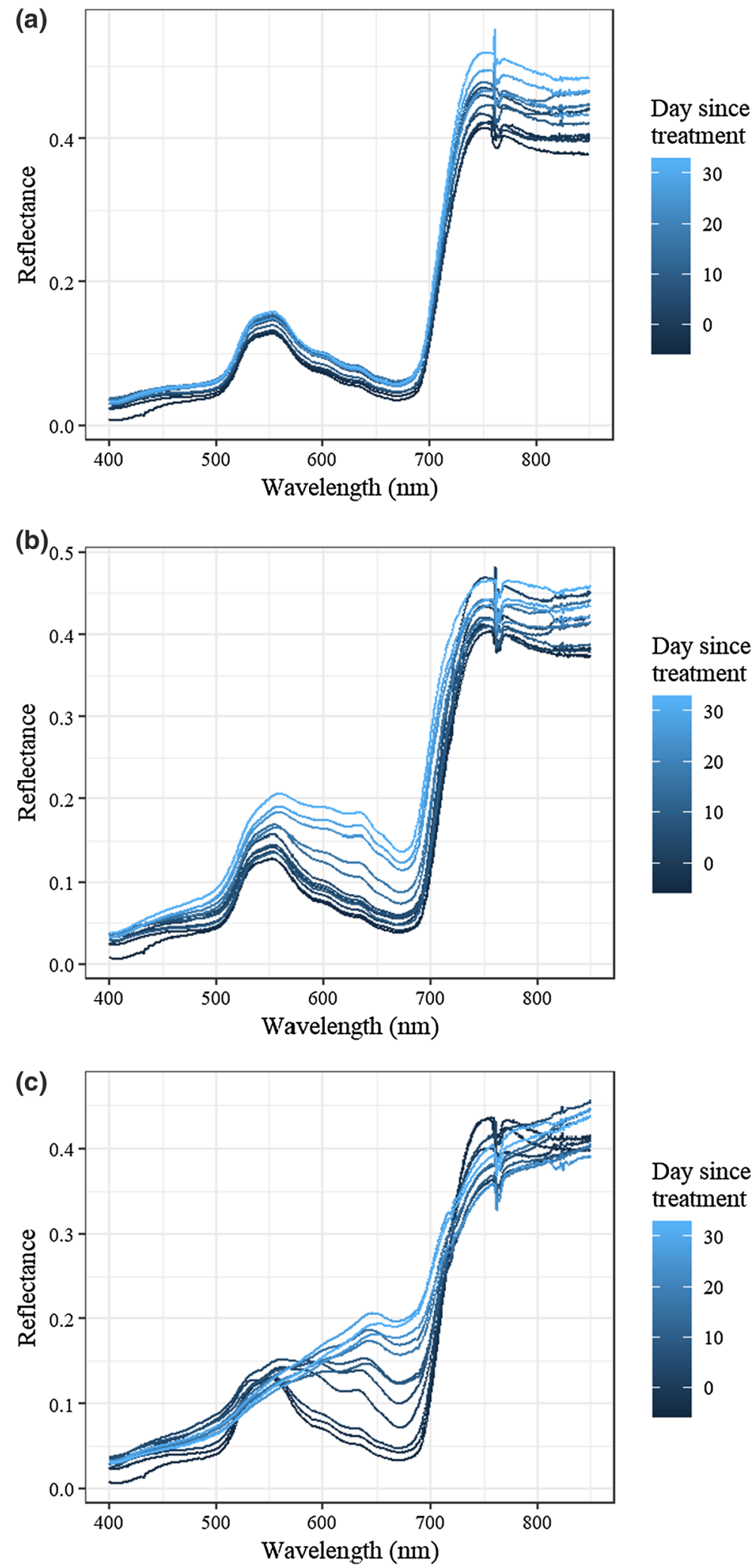

Day since treatment

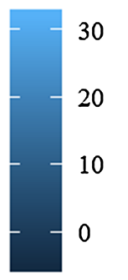

Day since treatment

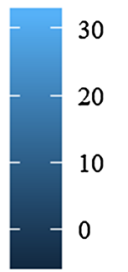


Fig. 3 Changes in $A, G$, ETR and $F_{\mathrm{v}} / F_{\mathrm{m}}$ over time for the three treatment groups before and following the application of herbicide to the two treatments at $T=0$. The control is represented by purple while yellow and green represent the application of triclopyr and diquat, respectively. The lines represent means for each treatment while the shaded area represents the mean \pm standard deviation
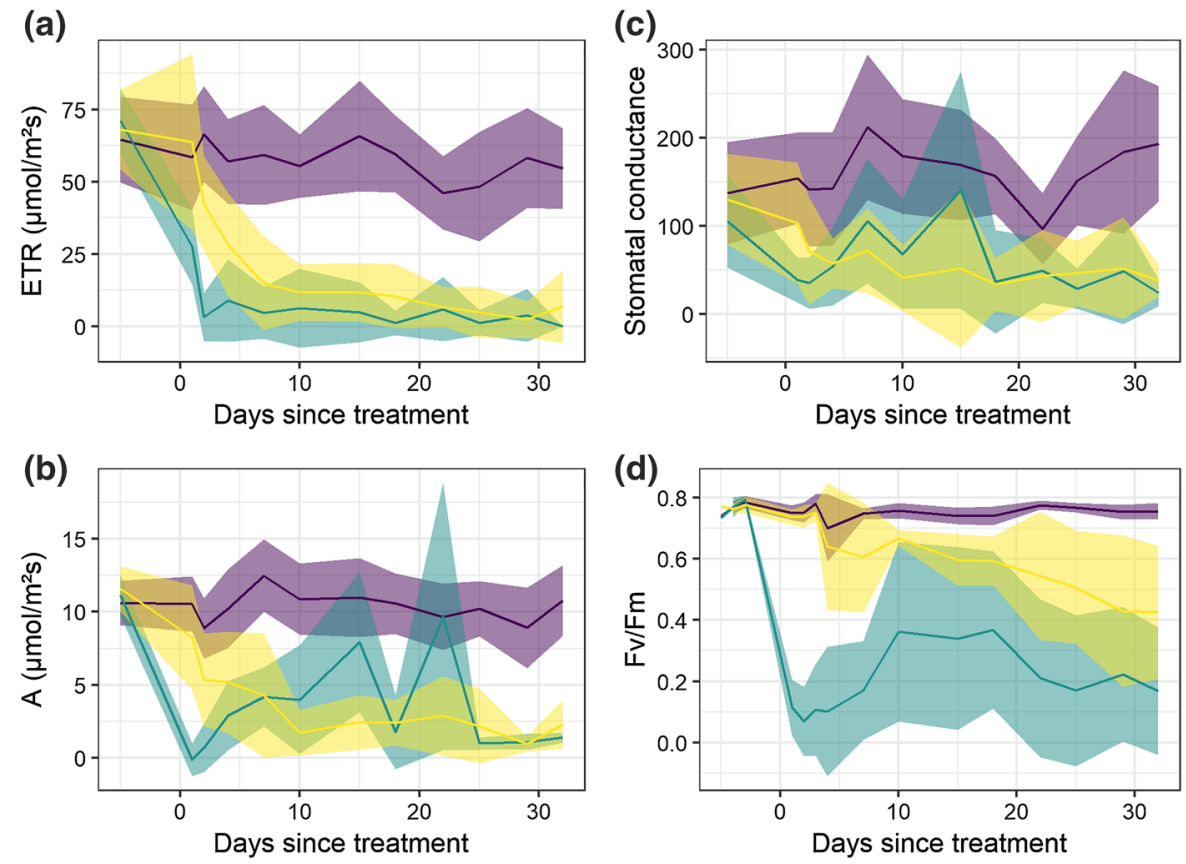
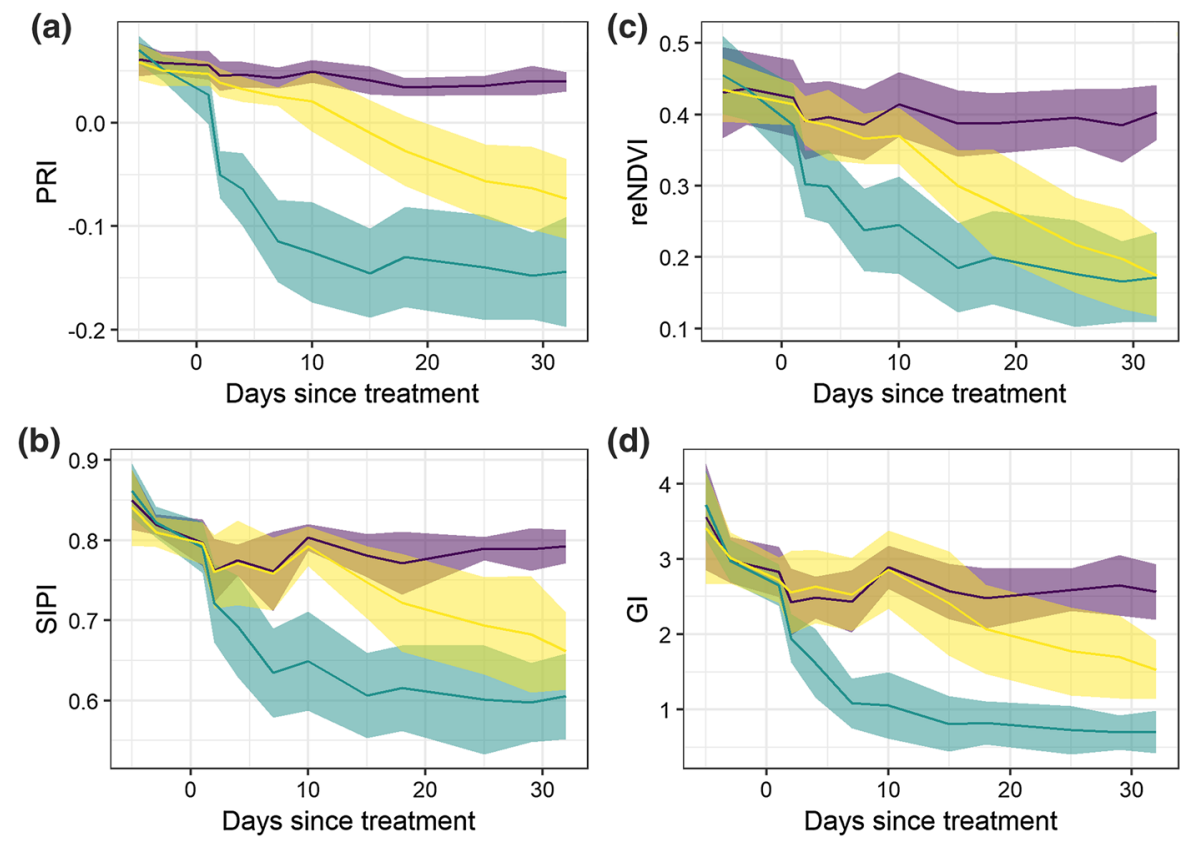

(d)

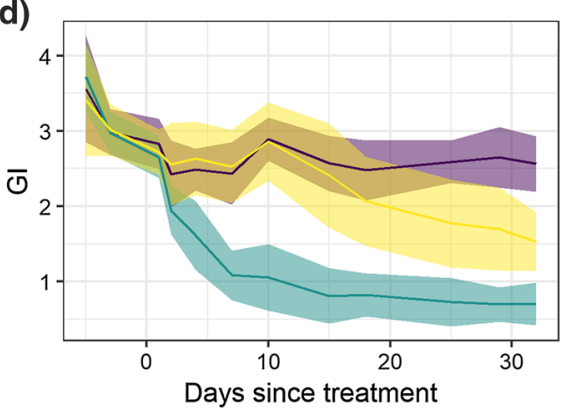

Fig. 4 Changes in PRI, reNDVI, SIPI and GI

derived from needle spectra over time for the three treatment groups before and following the application of herbicide to the two treatments at $T=0$. The control is represented by purple while yellow and green represent the application of triclopyr and diquat, respectively. The lines represent means for each treatment while the shaded area represents the mean \pm standard deviation in the changes through time in PRI. Values of PRI within this treatment declined slightly during week 2 and then more markedly after week 3, reaching minima 5 weeks after treatment.
Regression modelling

Of the indices tested, PRI exhibited the strongest correlation with the four photosynthetic parameters. As determined by the cross-validation, the coefficient of determination for relationships between PRI and $A$, $F_{\mathrm{v}} / F_{\mathrm{m}}, E T R$ and $G$ were, respectively, $0.53,0.46,0.68$ 
Fig. 5 Changes in the mean PRI, reNDVI, SIPI and GI over time for crown pixels of representative plants from each treatment before and following the application of herbicide to the two treatments at $T=0$. The control is represented by purple while yellow and green represent the application of triclopyr and diquat, respectively. The lines represent means for each treatment while the shaded area represents the mean \pm standard deviation
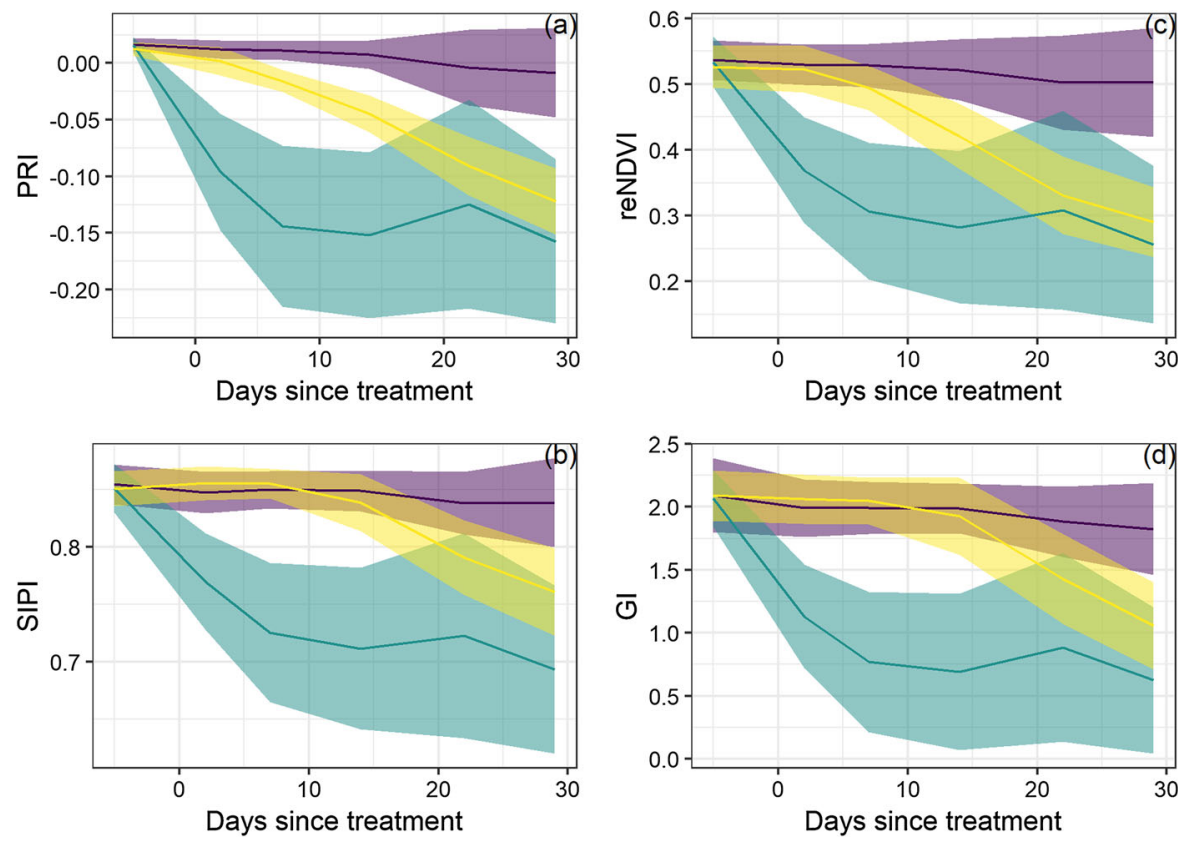

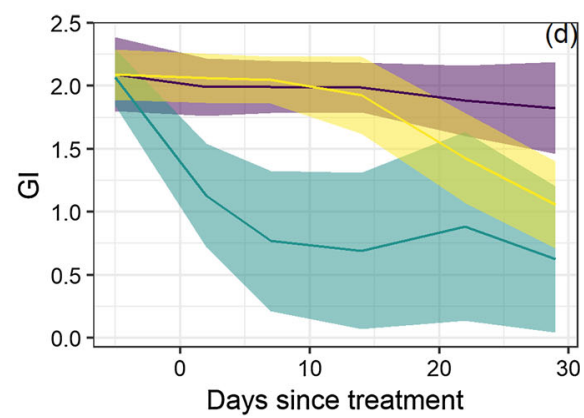

Table 5 The earliest day after treatment when the groups treated with diquat and triclopyr could be significantly differentiated from the control group using hyperspectral indices. The response variables modelled included the photochemical reflectance index (PRI), red edge NDVI, red edge index (Zarco-Tejada \& Miller), structure independent pigment index (SIPI), greenness index and NDVI

\begin{tabular}{llll}
\hline & Diquat & Triclopyr & Model $R^{2}$ \\
\hline PRI & Day 2 & Day 1 & 0.58 \\
Red edge NDVI & Day 2 & Day 10 & 0.91 \\
Red Edge Index & Day 1 & Day 10 & 0.90 \\
NDVI & Day 2 & Day 15 & 0.89 \\
SIPI & Day 2 & Day 18 & 0.85 \\
Greenness Index & Day 2 & Day 18 & 0.86 \\
\hline
\end{tabular}

and 0.29 (Table 6). Relationships between these parameters and PRI were best fitted by the sigmoidal Gompertz equation for $A, E T R$ and $G$ and by a linear model for $F_{\mathrm{v}} / F_{\mathrm{m}}$ (Fig. 7).

Model results showed that SPLS outperformed all other modelling approaches for all four photosynthetic parameters (Fig. 8). Sparse PLS proved superior at predicting $E T R, A$, and $\mathrm{G}$, and was at least as precise as the other models for $F_{\mathrm{v}} / F_{\mathrm{m}}$. Linear SVM and elastic net had similar precision and performed better than PLSR but were less precise than SPLS. For all response variables, PLSR had the lowest precision of all four modelling approaches. The best SPLS models were able to explain $64,62,65$ and $42 \%$ of the variance in $A, F_{\mathrm{v}} / F_{\mathrm{m}}, E T R$ and $G$, respectively.

\section{Discussion}

This study demonstrates the impact of two herbicide treatments, with contrasting modes of action, on needle discolouration, spectral properties and key physiological parameters. In contrast to diquat, which had an immediate effect the day after herbicide application, the impacts of triclopyr were expressed later with, for instance, $A$ reaching minima 29 days after application. Regardless of the mode of action, we found that the PRI was able to differentiate between the two herbicide treatments and the control within 2 days following treatments, which in the case of triclopyr preceded visual detection of discolouration by 6 days. In contrast to previous research (Hernández-Clemente et al. 2011) we found this index to be robust to scattering effects, which can be very strong in conifer tree crowns. Photochemical reflectance index was moderately associated with $A, F_{\mathrm{v}} / F_{\mathrm{m}}$ and strongly associated with ETR. With the exception of ETR more complex models developed using all spectra demonstrated a stronger association with $A$, 
Fig. 6 Variation in PRI between representative plants from each treatment for all acquisition times, with images on each row from top to bottom, representing the time of treatment $(0)$ followed by the 5 weeks following treatment $($ bottom $=$ week 5). Images shown in columns from left to right represent the control plant (plant 60) and plants treated with triclopyr (plant 51) and diquat (plant 6)
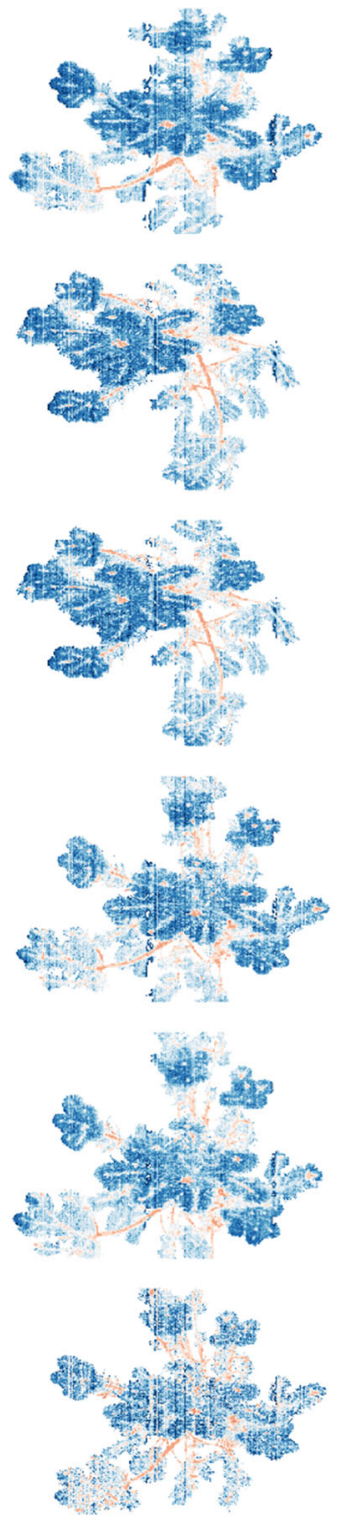

$F_{\mathrm{v}} / F_{\mathrm{m}}$ and $E T R$ and highlighted the importance of the green peak and red edge spectral regions for predictions.

It is likely that the early detection of stress using PRI was attributable to the close links of this index to $A, F_{\mathrm{v}} / F_{\mathrm{m}}$ and ETR, which also showed significant reductions in the first 2 days following treatment. The correlation between PRI and $F_{\mathrm{v}} / F_{\mathrm{m}}$, which provides a rapid assessment of PSII light use efficiency (LUE)
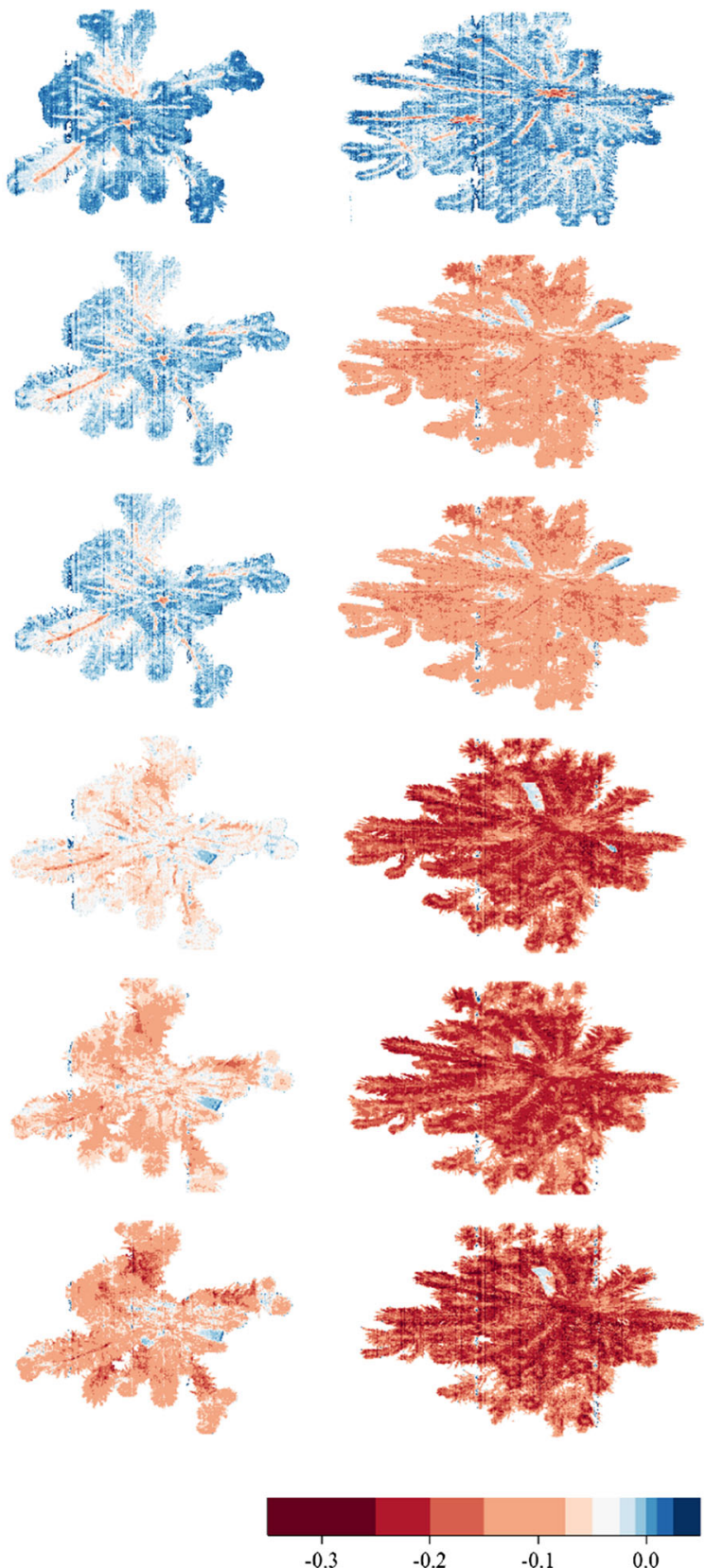

(Genty et al. 1989), is consistent with previous research that has found PRI useful to quantify changes in non-chemical quenching and LUE (Gamon et al. 1992; Hilker et al. 2008, 2012a, b; Middleton et al. 2009). In line with our findings, previous research has shown a strong correlation between PRI and photosynthetic rate in young beech trees subjected to two contrasting levels of drought stress (Buddenbaum et al. 2015). Research undertaken across a range of tree 
Table 6 Coefficient of determination between photosynthetic parameters and the vegetation indices used within this study. A range of model formulations were tested ranging from simple linear models to the sigmoidal Gompertz function

\begin{tabular}{lllll}
\hline & $A$ & ETR & $F_{\mathrm{v}} / F_{\mathrm{m}}$ & $G$ \\
\hline PRI & $\mathbf{0 . 5 2 7}$ & $\mathbf{0 . 6 8 2}$ & $\mathbf{0 . 4 6 4}$ & $\mathbf{0 . 2 8 8}$ \\
Red edge NDVI & 0.435 & 0.582 & 0.343 & 0.205 \\
NPQI & 0.040 & 0.049 & 0.022 & 0.012 \\
RESRI & 0.435 & 0.575 & 0.329 & 0.221 \\
NDVI & 0.342 & 0.502 & 0.383 & 0.164 \\
SIPI & 0.310 & 0.461 & 0.377 & 0.142 \\
Greenness Index & 0.280 & 0.433 & 0.389 & 0.097 \\
\hline
\end{tabular}

The $R^{2}$ for the index that was most strongly correlated to each photosynthetic parameter is highlighted in bold

species, including $P$. contorta, has also shown that diurnal and seasonal changes in photosynthetic activity can be accurately characterised using PRI (Gamon

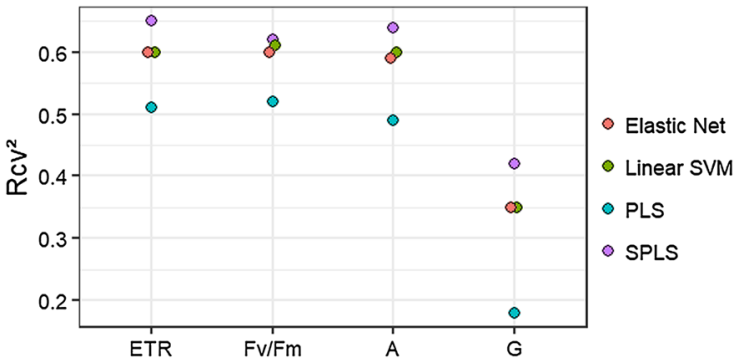

Fig. 8 Variation in the coefficient of determination $\left(R^{2}\right)$ between the four modelling methods for the photosynthetic parameters, ETR, $F_{\mathrm{v}} / F_{\mathrm{m}}, A$ and $G$

and Bond 2013; Wong and Gamon 2015). Our results extend this research to demonstrate the utility of PRI for detecting changes in photosynthesis resulting from herbicide application.

Significant improvements in model precision for $A$, $F_{\mathrm{v}} / F_{\mathrm{m}}$ and $G$ were found when all spectra were used to

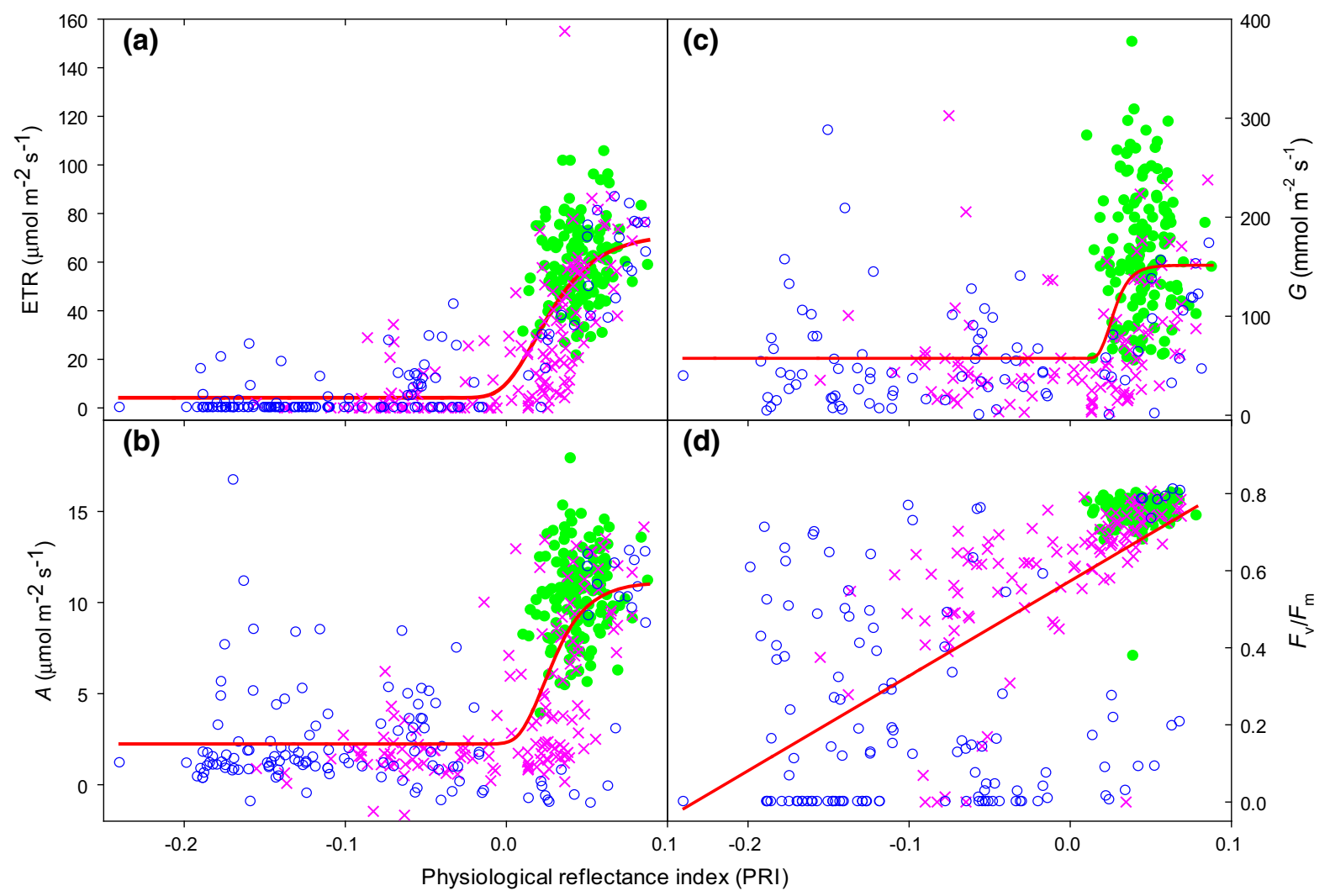

Fig. 7 Relationship between physiological reflectance index calculated form needle spectra and a electron transfer rate (ETR), b assimilation rate $(A)$, c stomatal conductance $(\mathrm{G})$ and d $F_{\mathrm{v}} / F_{\mathrm{m}}$ for control plants (green circles) and plants treated with triclopyr (pink crosses) and diquat (blue open circles). The red solid lines in each panel show lines fitted to the combined dataset 
predict the four photosynthetic parameters using more advanced methods.

These machine learning methods are well suited to analyses of hyperspectral data as they can handle high dimensionality, noisy data and inter-correlated features. Although there are a few examples of these methods being applied to hyperspectral data (Chan and Paelinckx 2008; Im et al. 2009; Melgani and Bruzzone 2002; Sluiter and Pebesma 2010; Zhao et al. 2008), these methods have not been widely used despite their considerable potential to improve model precision (e.g. Im et al. 2009). Our results highlighted significant variation among the four tested methods which is consistent with previous research that has used hyperspectral data to predict foliar $\mathrm{N}$ concentrations for a range of tree species. These previous studies show significant gains in precision through use of machine learning methods over that of partial least squares (Huang et al. 2004; Im et al. 2009) which in turn was more precise than regression (Huang et al. 2004; Im et al. 2009; Petisco et al. 2005). Our results build on these findings suggesting that sparse partial least squares may provide more precise predictions than partial least squares for applications that use hyperspectral imagery.

This research suggests that PRI may provide a useful method to monitor invasive conifers. Triclopyrbased formulations have been shown to be effective at killing wilding pines in field trials, although when used in isolation complete control is often not achieved and large trees frequently survive treatment (Gous et al. 2014, 2015). Research presented here suggests that remote monitoring of indices such as PRI is a useful approach for assessing the degree of damage following herbicide treatment and the potential need for further treatment.

Given the scale and scattered nature of infestations, satellite imagery is likely to provide the most appropriate data source to monitor the physiological state of sufficiently large dense stands of wilding pines. Studies have shown PRI derived from the MODIS satellite sensor (spatial resolution $1 \mathrm{~km}^{2}$ ) to be strongly correlated to LUE of boreal aspen (Drolet et al. 2005) and that these data can be used for regional mapping of LUE (Drolet et al. 2008). However, data acquired from hyperspectral satellites with a finer spatial and spectral resolution than MODIS is likely to be more appropriate for large scale monitoring especially if their orbits allow data acquisition over a large period of the day. The recently launched PRISMA and DESIS hyperspectral imagers, and the EnMAP sensor, which is scheduled for launch in 2020, are likely to be particularly suitable and will provide imagery at a spatial resolution of $30 \mathrm{~m}$ with a relatively fine spectral resolution of up to $6.5 \mathrm{~nm}$ within the VNIR range (Guanter et al. 2015). This will provide a powerful operational tool for monitoring the efficacy of control of herbicide applications on denser infestations. However, further research is needed to transfer these results from needle spectrometry and closerange imaging of single trees to a larger scale using satellite data. Monitoring of physiology in sparse infestations is likely to be particularly complex due to difficulties associated with delineating individual tree canopies and interpreting spectra from mixed pixels within these areas.

In conclusion, this study demonstrates the utility of hyperspectral data to detect the stress associated with herbicide damage. Although models of photosynthetic parameters developed from needle spectra had greater precision than those developed from PRI for three of the four photosynthetic parameters, the use of ratios such as PRI does have advantages. The use of reflectance ratios provides a useful means of mitigating against variation in atmospheric conditions and also reduces the confounding influence of leaf structure, leaf surface interactions and canopy structure (e.g. Penuelas et al. 1995a) which can improve model generality. Further research should focus on whether hyperspectral imagery and indices such as PRI can be used as an effective diagnostic of herbicide stress for wilding trees grown under typical field conditions and whether these findings can be applied to satellitebased observations.

Acknowledgements We are very grateful to Liam Wright for the wilding collection. Ben Morrow, Paul Keech, Caro Gous, Stefan Gous, Shideen Nathan assisted greatly with the practical aspects of the trial. The lead author appreciates the assistance of Max Bombrun for proofreading earlier versions of the manuscript and Jane Meiforth for helping organise the exchange, and for providing plenty of practical advice on New Zealand. This research was funded by the German Aerospace Center (DLR) and the German Federal Ministry of Economic Affairs and Energy in the framework of the EnMAP project, Grant Number 50 EE 1530. The research undertaken within New Zealand was funded by the Winning Against Wildings programme (Contract Number C09X1611) which was funded by the New Zealand Ministry for Business, Innovation, and Employment. This funding was supplemented by co-funding 
from the Forest Growers Levy Trust and Scion's Strategic Science Investment Fund.

Open Access This article is distributed under the terms of the Creative Commons Attribution 4.0 International License (http:// creativecommons.org/licenses/by/4.0/), which permits unrestricted use, distribution, and reproduction in any medium, provided you give appropriate credit to the original author(s) and the source, provide a link to the Creative Commons license, and indicate if changes were made.

\section{References}

Anon (2011) The right tree in the right place-New Zealand Wilding Conifer Management Strategy 2015-2030. Report prepared by the Ministry for Primary Industries

Asner GP, Martin RE (2009) Airborne spectranomics: mapping canopy chemical and taxonomic diversity in tropical forests. Front Ecol Environ 7:269-276

Buddenbaum H, Stern O, Stellmes M, Stoffels J, Pueschel P, Hill J, Werner W (2012) Field imaging spectroscopy of beech seedlings under dryness stress. Remote Sens 4:3721-3740

Buddenbaum H, Rock G, Hill J, Werner W (2015) Measuring stress reactions of beech seedlings with PRI, fluorescence, temperatures and emissivity from VNIR and thermal field imaging spectroscopy. Eur J Remote Sens 48:263-282

Chan JC-W, Paelinckx D (2008) Evaluation of Random Forest and Adaboost tree-based ensemble classification and spectral band selection for ecotope mapping using airborne hyperspectral imagery. Remote Sens Environ 112:2999-3011

Chauchard F, Cogdill R, Roussel S, Roger J, Bellon-Maurel V (2004) Application of LS-SVM to non-linear phenomena in NIR spectroscopy: development of a robust and portable sensor for acidity prediction in grapes. Chemometr Intell Lab Syst 71:141-150

Chun H, Keleş S (2010) Sparse partial least squares regression for simultaneous dimension reduction and variable selection. J R Stat Soc Ser B (Stat Methodol) 72:3-25

Cogliati S, Rossini M, Julitta T, Meroni M, Schickling A, Burkart A, Pinto F, Rascher U, Colombo R (2015) Continuous and long-term measurements of reflectance and sun-induced chlorophyll fluorescence by using novel automated field spectroscopy systems. Remote Sens Environ 164:270-281

Craig AP, Franca AS, Oliveira LS, Irudayaraj J, Ileleji K (2014) Application of elastic net and infrared spectroscopy in the discrimination between defective and non-defective roasted coffees. Talanta 128:393-400

Dash JP, Pearse GD, Watt MS, Paul T (2017a) Combining airborne laser scanning and aerial imagery enhances echo classification for invasive conifer detection. Remote Sens 9:156

Dash JP, Watt MS, Pearse GD, Heaphy M, Dungey HS (2017b) Assessing very high resolution UAV imagery for monitoring forest health during a simulated disease outbreak. ISPRS J Photogramm Remote Sens 131:1-14
Dash J, Pearse G, Watt M (2018) UAV multispectral imagery can complement satellite data for monitoring forest health. Remote Sens 10:1216

Drolet GG, Huemmrich KF, Hall FG, Middleton EM, Black TA, Barr AG, Margolis HA (2005) A MODIS-derived photochemical reflectance index to detect inter-annual variations in the photosynthetic light-use efficiency of a boreal deciduous forest. Remote Sens Environ 98:212-224

Drolet G, Middleton E, Huemmrich K, Hall F, Amiro B, Barr A, Black T, McCaughey J, Margolis H (2008) Regional mapping of gross light-use efficiency using MODIS spectral indices. Remote Sens Environ 112:3064-3078

Dyar M, Carmosino M, Breves E, Ozanne M, Clegg S, Wiens R (2012) Comparison of partial least squares and lasso regression techniques as applied to laser-induced breakdown spectroscopy of geological samples. Spectrochim Acta Part B 70:51-67

Farjon A, Farjon A (2008) A natural history of conifers. Timber Press, Portland

Filzmoser P, Gschwandtner M, Todorov V (2012) Review of sparse methods in regression and classification with application to chemometrics. J Chemom 26:42-51

Friedman J, Hastie T, Tibshirani R (2010) Regularization paths for generalized linear models via coordinate descent. J Stat Softw 33:1

Fu G-H, Xu Q-S, Li H-D, Cao D-S, Liang Y-Z (2011) Elastic net grouping variable selection combined with partial least squares regression (EN-PLSR) for the analysis of strongly multi-collinear spectroscopic data. Appl Spectrosc 65:402-408

Gamon JA, Bond B (2013) Effects of irradiance and photosynthetic downregulation on the photochemical reflectance index in Douglas-fir and ponderosa pine. Remote Sens Environ 135:141-149

Gamon J, Penuelas J, Field C (1992) A narrow-waveband spectral index that tracks diurnal changes in photosynthetic efficiency. Remote Sens Environ 41:35-44

Gamon J, Serrano L, Surfus J (1997) The photochemical reflectance index: an optical indicator of photosynthetic radiation use efficiency across species, functional types, and nutrient levels. Oecologia 112:492-501

Garrett LG, Watt MS, Pearce SH (2016) Environmental fate of terbuthylazine and hexazinone in a planted forest steepland recent soil, New Zealand. N Z J Forest Sci 46:17

Genty B, Briantais J-M, Baker NR (1989) The relationship between the quantum yield of photosynthetic electron transport and quenching of chlorophyll fluorescence. Biochimica et Biophysica Acta (BBA)-General Subjects 990:87-92

Gous SF, Watt MS, Richardson B, Kimberley MO (2010) Herbicide screening trial to control dormant wilding Pinus contora, P. mugo and Pseudotsuga menziesii during winter. N Z J For Sci 40:153-159

Gous S, Raal P, Watt MS (2014) Aerial spot treatment using an oil carrier to apply ester based herbicides for control of Pinus contorta and $P$. nigra in New Zealand. N Z J For Sci 44:23

Gous S, Raal P, Watt MS (2015) The evaluation of aerially applied triclopyr mixtures for the control of dense infestations of wilding Pinus contorta in New Zealand. N Z J For Sci 45:1 
Guanter L, Kaufmann H, Segl K, Foerster S, Rogass C, Chabrillat S, Kuester T, Hollstein A, Rossner G, Chlebek C (2015) The EnMAP spaceborne imaging spectroscopy mission for earth observation. Remote Sens 7:8830-8857

Hernández-Clemente R, Navarro-Cerrillo RM, Suárez L, Morales F, Zarco-Tejada PJ (2011) Assessing structural effects on PRI for stress detection in conifer forests. Remote Sens Environ 115:2360-2375

Hilker T, Coops NC, Hall FG, Black TA, Chen B, Krishnan P, Wulder MA, Sellers PJ, Middleton EM, Huemmrich KF (2008) A modeling approach for upscaling gross ecosystem production to the landscape scale using remote sensing data. J Geophys Res Biogeosci 113:G03006

Hilker T, Coops NC, Culvenor DS, Newnham G, Wulder MA, Bater CW, Siggins A (2012a) A simple technique for coregistration of terrestrial LiDAR observations for forestry applications. Remote Sens Lett 3:239-247

Hilker T, Hall FG, Tucker CJ, Coops NC, Black TA, Nichol CJ, Sellers PJ, Barr A, Hollinger DY, Munger J (2012b) Data assimilation of photosynthetic light-use efficiency using multi-angular satellite data: II Model implementation and validation. Remote Sens Environ 121:287-300

Hill J, Buddenbaum H, Townsend PA (2019) Imaging spectroscopy of forest ecosystems: perspectives for the use of space-borne hyperspectral earth observation systems. Surv Geophys 40:553-588

Höskuldsson A (2001) Variable and subset selection in PLS regression. Chemometr Intell Lab Syst 55:23-38

Huang Z, Turner BJ, Dury SJ, Wallis IR, Foley WJ (2004) Estimating foliage nitrogen concentration from HYMAP data using continuum removal analysis. Remote Sens Environ 93:18-29

Huang Y, Thomson SJ, Ortiz BV, Reddy KN, Ding W, Zablotowicz RM, Bright JR (2010) Airborne remote sensing assessment of the damage to cotton caused by spray drift from aerially applied glyphosate through spray deposition measurements. Biosyst Eng 107:212-220

Im J, Jensen JR, Coleman M, Nelson E (2009) Hyperspectral remote sensing analysis of short rotation woody crops grown with controlled nutrient and irrigation treatments. Geocarto Int 24:293-312

Jacquemoud S, Baret F (1990) PROSPECT: a model of leaf optical properties spectra. Remote Sens Environ 34:75-91

Karatzoglou A, Smola A, Hornik K, Zeileis A (2004) kernlab-an S4 package for kernel methods in R. J Stat Softw 11:1-20

Kuhn M (2008) Building predictive models in R using the caret package. J Stat Softw 28:1-26. https://doi.org/10.18637/ jss.v028.i05

Mason NWH, Palmer DJ, Vetrova V, Brabyn L, Paul T, Willemse P, Peltzer DA (2017) Accentuating the positive while eliminating the negative of alien tree invasions: a multiple ecosystem services approach to prioritising control efforts. Biol Invasions 19:1181-1195

McAlpine KG, Howell CJ, Wotton DM (2016) Effects of tree control method, seed addition, and introduced mammal exclusion on seedling establishment in an invasive Pinus contorta forest. N Z J Ecol 40:302-309

Melgani F, Bruzzone L (2002) Support vector machines for classification of hyperspectral remote-sensing images. In: Geoscience and remote sensing symposium, 2002. IGARSS'02. 2002 IEEE International. IEEE, pp. 506-508
Mevik B-H, Wehrens R, Liland KH (2011) pls: partial least squares and principal component regression. $\mathrm{R}$ package version

Middleton EM, Cheng Y-B, Hilker T, Black TA, Krishnan P, Coops NC, Huemmrich KF (2009) Linking foliage spectral responses to canopy-level ecosystem photosynthetic lightuse efficiency at a Douglas-fir forest in Canada. Can J Remote Sens 35:166-188

Moresco R, Afonso T, Uarrota VG, Navarro BB, Nunes EdC, Rocha M, Maraschin M (2017) Classification tools for carotenoid content estimation in Manihot esculenta via Metabolomics and machine learning. In: International conference on practical applications of computational biology \& bioinformatics. Springer, pp 280-288

Moya I, Flexas J (2012) Remote sensing of photosynthesis. In: Flexas J, Loreto F, Medrane H (eds) Terrestrial photosynthesis in a changing environment: a molecular, physiological and ecological approach. Cambridge University Press, Cambridge, pp 219-236

Nguyen DV, Rocke DM (2002) Tumor classification by partial least squares using microarray gene expression data. Bioinformatics 18:39-50

Nuñez MA, Chiuffo MC, Torres A, Paul T, Dimarco RD, Raal P, Policelli N, Moyano J, García RA, Van Wilgen BW, Pauchard A, Richardson DM (2017) Ecology and management of invasive Pinaceae around the world: progress and challenges. Biol Invasions 19:3099-3120

NZFOA (2018) Facts and figures 2017/2018. New Zealand Forest Owners Association, Wellington, p 60

Penuelas J, Baret F, Filella I (1995a) Semi-empirical indices to assess carotenoids/chlorophyll a ratio from leaf spectral reflectance. Photosynthetica 31:221-230

Penuelas J, Filella I, Lloret P, Munoz F, Vilajeliu M (1995b) Reflectance assessment of plant mite attack on apple trees. Int J Remote Sens 16:2727-2733

Petisco C, García-Criado B, De Aldana BV, Zabalgogeazcoa I, Mediavilla S (2005) Use of near-infrared reflectance spectroscopy in predicting nitrogen, phosphorus and calcium contents in heterogeneous woody plant species. Anal Bioanal Chem 382:458-465

Pinheiro J, Bates D, DebRoy S, Sarkar D (2014) Linear and nonlinear mixed effects models. R package version

Pinheiro J, Bates D, DebRoy S, Sarkar D (2018) nlme: linear and nonlinear mixed effects models, $\mathrm{R}$ package version 3.1137. R Core Team

Richardson DM, Rejmanek M (2004) Conifers as invasive aliens: a global survey and predictive framework. Divers Distrib 10:321-331

Richardson DM, Rejmánek M (2011) Trees and shrubs as invasive alien species-a global review. Divers Distrib 17:788-809

Richardson DM, Hui C, Nuñez MA, Pauchard A (2014) Tree invasions: patterns, processes, challenges and opportunities. Biol Invasions 16:473-481

Rouse Jr, J, Haas RH, Schell JA, Deering DW (1974) Monitoring vegetation systems in the Great Plains with ERTS'. In: Third ERTS symposium, NASA SP-351 I, pp 309-317

Sherwani SI, Arif I, Khan HA (2015) Modes of action of different classes of herbicides. In: Price A, Kelton J, Sarunaite L (eds) Herbicides, physiology of action and safety. 
IntechOpen, England. https://doi.org/10.5772/61779. ISBN 978-953-51-2217-3

Sluiter R, Pebesma E (2010) Comparing techniques for vegetation classification using multi-and hyperspectral images and ancillary environmental data. Int $\mathbf{J}$ Remote Sens 31:6143-6161

R Development Core Team (2014) R: A language and environment for statistical computing. R Foundation for Statistical Computing, Vienna, Austria. http://www.R-project. org/

Thissen U, Pepers M, Üstün B, Melssen W, Buydens L (2004) Comparing support vector machines to PLS for spectral regression applications. Chemometr Intell Lab Syst 73:169-179

Tu M, Hurd C, Randall JM (2001) Weed control methods handbook: tools and techniques for use in natural areas. All U.S. Government Documents, Paper 533. https:// digitalcommons.usu.edu/govtdocs/533

Vapnik V (2013) The nature of statistical learning theory. Springer, Berlin

Wang L-L, Lin Y-W, Wang X-F, Xiao N, Xu Y-D, Li H-D, Xu Q-S (2017) A selective review and comparison for interval variable selection in spectroscopic modeling. Chemom Intell Lab Syst 172:229

Wold H (1966) Estimation of principal components and related models by iterative least squares. In: Krishnaiah PR (ed) Multivariate analysis. Academic Press, New York

Wold S, Sjöström M, Eriksson L (2001) PLS-regression: a basic tool of chemometrics. Chemometr Intell Lab Syst 58:109-130

Wong CY, Gamon JA (2015) The photochemical reflectance index provides an optical indicator of spring photosynthetic activation in evergreen conifers. New Phytol 206:196-208

Yao H, Huang Y, Hruska Z, Thomson SJ, Reddy KN (2012) Using vegetation index and modified derivative for early detection of soybean plant injury from glyphosate. Comput Electron Agric 89:145-157

Zarco-Tejada PJ, Miller JR, Noland TL, Mohammed GH, Sampson PH (2001) Scaling-up and model inversion methods with narrowband optical indices for chlorophyll content estimation in closed forest canopies with hyperspectral data. IEEE Trans Geosci Remote Sens 39:1491-1507

Zarco-Tejada P, Miller J, Morales A, Berjón A, Agüera J (2004) Hyperspectral indices and model simulation for chlorophyll estimation in open-canopy tree crops. Remote Sens Environ 90:463-476

Zhao K, Popescu S, Zhang X (2008) Bayesian learning with Gaussian processes for supervised classification of hyperspectral data. Photogramm Eng Remote Sens 74:1223-1234

Zhao F, Guo Y, Huang Y, Reddy KN, Lee MA, Fletcher RS, Thomson SJ (2014) Early detection of crop injury from herbicide glyphosate by leaf biochemical parameter inversion. Int J Appl Earth Obs Geoinf 31:78-85

Zou H, Hastie T (2005) Regularization and variable selection via the elastic net. J R Stat Soc Ser B (Stat Methodol) 67:301-320

Publisher's Note Springer Nature remains neutral with regard to jurisdictional claims in published maps and institutional affiliations. 